\title{
Mode II Fracture Toughness of Hybrid FRCs
}

\author{
H. S. S. Abou El-Mal ${ }^{1)}$, A. S. Sherbini' ${ }^{2)}$, and H. E. M. Sallam ${ }^{3), *}$
}

(Received June 11, 2015, Accepted October 25, 2015, Published online November 27, 2015)

\begin{abstract}
Mode II fracture toughness $\left(K_{I C}\right)$ of fiber reinforced concrete $(\mathrm{FRC})$ has been widely investigated under various patterns of test specimen geometries. Most of these studies were focused on single type fiber reinforced concrete. There is a lack in such studies for hybrid fiber reinforced concrete. In the current study, an experimental investigation of evaluating mode II fracture toughness $\left(K_{I I C}\right)$ of hybrid fiber embedded in high strength concrete matrix has been reported. Three different types of fibers; namely steel (S), glass (G), and polypropylene (PP) fibers were mixed together in four hybridization patterns (S/G), (S/PP), (G/PP), $(\mathrm{S} / \mathrm{G} / \mathrm{PP})$ with constant cumulative volume fraction $\left(V_{f}\right)$ of $1.5 \%$. The concrete matrix properties were kept the same for all hybrid FRC patterns. In an attempt to estimate a fairly accepted value of fracture toughness $K_{\text {IIc }}$, four testing geometries and loading types are employed in this investigation. Three different ratios of notch depth to specimen width $(a / w) 0.3,0.4$, and 0.5 were implemented in this study. Mode II fracture toughness of concrete $K_{I I c}$ was found to decrease with the increment of a/w ratio for all concretes and test geometries. Mode II fracture toughness $K_{I I c}$ was sensitive to the hybridization patterns of fiber. The (S/PP) hybridization pattern showed higher values than all other patterns, while the (S/G/PP) showed insignificant enhancement on mode II fracture toughness $\left(K_{I I c}\right)$. The four point shear test set up reflected the lowest values of mode II fracture toughness $K_{\text {IIc }}$ of concrete. The non damage defect concept proved that, double edge notch prism test setup is the most reliable test to measure pure mode II of concrete.
\end{abstract}

Keywords: fiber reinforced concrete, hybrid fiber, mode II fracture toughness.

\section{Introduction}

Almost all FRCs used today commercially involve the use of a single fiber type. The decision to mix two fibers may be based on the properties that they may individually provide or simply based on economics (ACI committee 544 2011). Clearly, a given type of fiber can only be effective in a limited range of crack opening and deflection. The benefits of combining organic and inorganic fibers to achieve superior tensile strength and fracture toughness were recognized nearly 40 years ago by Walton and Majumdar (1975). After a long period of relative inactivity there appears to be a second wave of interest in hybrid fiber composites and efforts are underway to develop the science and rationale behind fiber hybridization.

In well-designed hybrid composites, there is a positive interaction between the fibers and the resulting hybrid

\footnotetext{
${ }^{1)}$ Civil Engineering Department, Menofia University, Shibin El-Kom 32511, Egypt.

${ }^{2)}$ Civil Engineering Department, Suez Canal University, Ismailya 41522, Egypt.

${ }^{3)}$ Department of Civil Engineering, Faculty of Engineering, Jazan University, Jazan 82822-6694, Saudi Arabia.

*Corresponding Author; E-mail: hem_sallam@yahoo.com Copyright $($ The Author(s) 2015. This article is published with open access at Springerlink.com
}

performance exceeds the sum of individual fiber performances (Bentur and Mindess 1990; Xu et al. 1998). This phenomenon is often termed as "synergy". This might be due to any of the following mechanisms.

\subsection{Hybrids Based on Fiber Constitutive Response}

One type of fiber is stronger, stiffer and provides reasonable first crack strength and ultimate strength, while the second type of fiber is relatively flexible and leads to improved toughness and strain capacity in the post-crack zone.

\subsection{Hybrids Based on Fiber Dimensions}

One type of fiber is smaller, so that it bridges micro-cracks controlling their growth and delays coalescence. This leads to a higher tensile strength of the composite. The second fiber is larger and is intended to arrest the propagation of macro-cracks and therefore results in a substantial improvement in the fracture toughness of the composite. Fibers of small size (often called micro-fibers) delay crack coalescence in the cement paste and mortar phases and increase the apparent tensile strength of these phases (Banthia et al. 1995; Shah 1991).

\subsection{Hybrids Based on Fiber Function}

One type of fiber is intended to improve the fresh and early age properties such as ease of production and plastic 
shrinkage, while the second fiber leads to improved mechanical properties.

In the past, many attempts have been made at identifying fiber combinations that produce the maximum synergy (Larson and Krenchel 1991; Feldman and Zheng 1993; Kamlos et al. 1995; Qian and Stroeven 2000; Kim et al. 1999; Banthia and Sheng 1991; Mobasher and Li 1996; Lawler et al. 2002). More recently, Banthia and Soleimani (2005) investigated three-fiber hybrids with carbon and polypropylene microfibers added to macro-steel fibers. Their results showed that, steel macro-fibers with highly deformed geometry produce better three-fiber hybrids than those with a less deformed geometry. Finally, Banthia and Gupta (2004) showed that the strength of the matrix plays a major role in the optimization of hybrid composites.

On the other hand, many researchers are now looking at the sliding plane deformation state other than opening mode which may be associated with crack propagation and fracture known as mode II fracture. In considering this, there are two major and interrelated problems: (1) determination of fracture parameters for mode II and (2) verification both analytically and experimentally that a crack can propagate due to mode II deformation. Analytical models cannot function successfully without valid mode II data such as values of $K_{\text {IIc }}$ (Swartz et al. 1988). The authors' knowledge to the parameters controlling the concrete fracture toughness and the fiber/matrix interface should enhance the development of concrete technology.

To study Mode II fracture toughness, various approaches have attempted to define testing geometries where selfsimilar crack propagation occurs with only mode II deformations (Sherbini 2014). Although there is a violent debate around the validity of such a test in driving cracks under pure mode II, the proposed test geometries briefed in Table 1 are considered the most important techniques in isolating shear parameters (Reinhardt et al. 1997; Watkins 1983; Prokopski 1991; Irobe and Pen 1992; Iosipescu 1967).

In a quick comparison between advantages and disadvantages of proposed Mode II fracture toughness test approaches, Sherbini (2014) concluded in an earlier study that, double notched cube (DNC) test setup showed higher values than all other tests due to the crack propagation miss alignment opposing sliding of crack surfaces. Regarding Brazilian notched disc (BND) test setup, the addition of fibers decreased the calculated values of $K_{I I c}$ for all single fiber types. Finally, four point shear (4PS) test set up reflects the most reliable values of mode II fracture toughness $K_{I I C}$ of concrete. The biases of the various concrete toughness tests developed is still unknown. Sufficient data should be gathered and sufficient research conclusions should be collected in order to define a reliable test standard (Lee and Lopez 2014).

The aim of this experimental investigation is to study the effect of adding different combinations of fibers to concrete on its mode II fracture toughness $K_{I I c}$. A comparison between the estimated values of $K_{I I c}$ of concrete according to the proposed four different test techniques is reported in this investigation attempting to find an answer for the confusing argument, "which test set up is the most convenient to evaluate mode II fracture toughness in case of hybrid fiber reinforced concrete?"

\section{Experimental Work}

The present experimental program included Three different types of fibers; namely steel $(S)$, glass $(G)$, and polypropylene (PP) fibers were mixed together in four hybridization groups, (S/G), (S/PP), (G/PP), (S/G/PP) with constant cumulative volume fraction $\left(V_{f}\right)$ of $1.5 \%$. The concrete matrix properties were kept the same for all hybrid fiber reinforced concrete (FRC) patterns. The chosen types of fibers, cumulative volume fractions $\left(V_{f}\right)$, properties of raw materials, mix proportions, matrix properties, and all other laboratory conditions (specimen preparation, casting and compaction, curing, temperature, test setup, and day of testing) were kept the same as reported from previous work of Sherbini (2014) to achieve a solid comparison with his earlier study for single fiber type. Each group contains, standard cubes and cylinders to determine the mechanical properties, in addition to four different mode II fracture toughness test specimens (Reinhardt et al. 1997; Watkins 1983; Prokopski 1991; Irobe and Pen 1992; Iosipescu 1967). In the current study, three different $(a / w)$ ratios 0.3 , 0.4 , and 0.5 were used in agreement with the conclusion of Lee and Lopez (2014) that, the accuracy of the size effect fracture energy determined using one size of notched beam has recently been brought into question. As a further study, a comparison of the size effect fracture energy as determined using multiple sizes of notched beams is recommended. Five specimens per sample were used for each tested parameter.

The cement used in all concrete mixes was ordinary Portland cement of $450 \mathrm{~kg} / \mathrm{m}^{3}$. Light gray silica fume with specific surface area (SSA) of $18 \mathrm{~m}^{2} / \mathrm{gm}$ supplied from the Ferro silicon alloys plant in Edfo zone, Egypt, was used with $10 \%$ added percentage to the cement content to produce HSC. The sand used was local natural siliceous sand with specific gravity of 2.55, fineness modulus (FM) of 2.51, and SSA of $50.47 \mathrm{~cm}^{2} / \mathrm{gm}$. The coarse aggregate was dolomite with nominal maximum aggregate size (NMAS) of $10 \mathrm{~mm}$, specific gravity of 2.6, FM of 6.69 , and SSA of $6.54 \mathrm{~cm}^{2}$ / gm. A superplasticizer called Adecrite PVF (naphthalene sulphonated compound) was added to the mixing water to improve the workability and to keep the slump almost constant. The mixing, casting, and compaction recommendations suggested by ACI Committee 544 (2011) were adopted in the present work to prepare all mixes.

Plain mild steel, high zirconia alkali resistance glass (NEG $\mathrm{ARG}$ ) fibers and $\mathrm{MC}$ polypropylene fibers were used with different combinations in this investigation. Table 2 shows the properties of different fiber types used in the current study as reported by manufacturers. Galvanized steel fiber with a new shape was used in this work; two straight steel 
Table 1 Mode II fracture toughness test geometries.

\begin{tabular}{|c|c|c|}
\hline Test geometries & Calculation equation & Dimensions mm \\
\hline 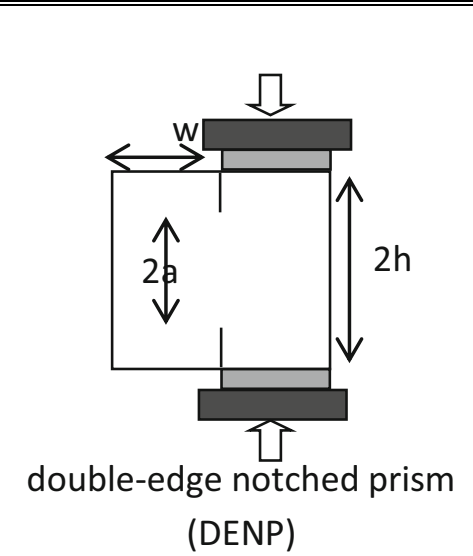 & $\begin{array}{l}\text { If } h \geq 2 a, w \geq \pi a . K_{I I c}=\frac{\sigma}{4}(\pi a)^{1 / 2} \\
\quad \text { If } h \geq 2 a, w \leq \pi a K_{I I c}=\frac{\sigma}{4} w^{1 / 2} \\
\text { Proposed by Reinhardt et al. (1997) }\end{array}$ & $\begin{array}{c}2 h=200 \\
2 a=140,120,100 \\
w=100 \\
\text { Thickness }=100\end{array}$ \\
\hline Double notched cube & $\begin{array}{c}K_{I I c}=\frac{5.11 P_{Q}}{2 B W}(\pi a)^{1 / 2} \\
\text { Proposed by Watkins (1983) and Prokopski (1991) }\end{array}$ & $\begin{array}{c}\text { Cube } 150 \mathrm{~mm} \\
\begin{array}{c}a=45,60,75 \\
w=150 \\
B=w-a\end{array}\end{array}$ \\
\hline $\begin{array}{c}\text { Brazilian Disc Specimen } \\
\text { with inclined centered notch } \\
\text { (BND) }\end{array}$ & $\begin{array}{c}K_{I I c}=-\frac{2 P}{t} \sqrt{\frac{\lambda}{\pi R}}\left\{\begin{array}{c}B_{0}-\lambda^{2}\left(B_{0}+\frac{1}{2} B_{2}\right)+\lambda^{4}\left(-\frac{1}{8} B_{0}+\frac{1}{4} B_{2}+\frac{3}{8} B_{4}\right) \\
+\lambda^{6}\left(B_{0}-\frac{1}{16} B_{2}+\frac{1}{8} B_{4}+\frac{5}{16} B_{6}\right) \\
+\lambda^{8}\left(-\frac{17}{64} B_{0}+\frac{3}{8} B_{2}-\frac{5}{128} B_{4}+\frac{5}{64} B_{6}+\frac{35}{128} B_{8}\right)\end{array}\right) \\
\lambda=a / R \text {, and } \beta: \text { the notch inclination angle }=30^{\circ} \\
B_{0}=\sin 2 \beta, \mathrm{B}_{2}=2[\sin 4 \beta-\sin 2 \beta], \\
\mathrm{B}_{4}=3[\sin 6 \beta-2 \sin 4 \beta] . \\
B_{6}=4[\sin 8 \beta-3 \sin 6 \beta], B_{8}=5[\sin 10 \beta-4 \sin 8 \beta] . \\
\text { Proposed by Irobe and Pen }(1992)\end{array}$ & $\begin{array}{c}\beta=30^{\circ} \\
R=75 \\
\text { Thickness }=60 \\
2 a=45,60,75\end{array}$ \\
\hline Four-Point Shear Beam & $\begin{array}{c}K_{I I c}=Y_{I I} \sigma \sqrt{\pi a} \\
\text { Proposed by Iosipescu (1967) }\end{array}$ & $\begin{array}{c}\text { Prism } 100 \times 100 \times 500 \\
\qquad a=30,40,50 \\
\text { Loaded span }=400\end{array}$ \\
\hline
\end{tabular}


Table 2 Properties of the used steel, glass and polypropylene fiber.

\begin{tabular}{c|c|c|c}
\hline \multirow{2}{*}{ Properties } & \multicolumn{3}{|c}{ Fibers type } \\
\cline { 2 - 4 } & Plain mild steel & NEG ARG glass & MC polypropylene* \\
\hline \hline Fiber length $(\mathrm{mm})$ & 25 & 25 & 15 \\
\hline Fiber diameter & $\begin{array}{c}0.5 \mathrm{~mm} / \text { filament } \\
1 \mathrm{~mm} / \mathrm{bi} \text {-filament }\end{array}$ & $\begin{array}{c}10-12 \mu \mathrm{m} / \text { filament } \\
1-1.2 \mathrm{~mm} / \mathrm{strand}\end{array}$ & $0.0965 \pm 10 \%{ }^{* *}$ \\
\hline Specific gravity $\left(\mathrm{t} / \mathrm{m}^{3}\right)$ & 7.8 & 2.7 & 0.90 \\
\hline Tensile strength $(\mathrm{MPa})$ & 3600 & 1400 & $550-600$ \\
\hline Young's modulus $(\mathrm{MPa})$ & 200,000 & 74,000 & $3600-3900$ \\
\hline Strain at failure $(\%)$ & $6-9$ & 2 & $14-25$ \\
\hline Geometry & Bi-filament & Chopped strands & Monofilament \\
\hline
\end{tabular}

* Master Chemicals Technology Company.

** Fiber thickness (mm).

Table 3 Fiber combination percentages.

\begin{tabular}{c|c|c|c|c}
\hline & S/G & S/PP & G/P & S/G/P \\
\hline \hline Volume fraction $\left(V_{f}\right)$ & $1 \%$ steel \& $0.5 \%$ glass & $1 \%$ steel \& $0.5 \%$ PP & $0.75 \%$ glass \& $0.75 \%$ PP & $0.5 \%$ steel \& $0.5 \%$ glass \& \\
& & & & $0.5 \%$ PP \\
\hline
\end{tabular}

fibers of $265 \mathrm{MPa}$ yield strength were twisted around each other to form a bi-filament fiber of $25 \mathrm{~mm}$ length. This new shape of fiber produces a good bond between the matrix and the fiber due to the development of interlock mechanical bond depending on the fiber geometry. Chopped strands alkaline resistance glass fiber (NEG ARG) achieves its high alkali resistance from the high zirconia's content in its glass composition. "MC" polypropylene Synthetic fiber meets the requirements of ASTM C 1116 and C 1399.

The mix proportion by weight for all mixes was 1:1.92:2.00:0.38 [cement:sand:dolomite:water/(cementations materials)] as reported by Sherbini (2014). The fiber combination percentages are illustrated in Table 3 .

A vertical mixer of revolving blades type was used in mixing. Materials of the specified mix were weighed first and then mixed in the following procedures. Mixing different fiber types in hybrid combinations was really a challenge. The used fibers with widely varied aspect ratios are hard to blend together due to their different behavior during mixing. Polypropylene fibers representing high aspect ratio fiber $(L / d=167)$ should be mixed with the fine dry components.

First of all: sand, cement, silica fume, and polypropylene fibers were dryly mixed together for about $3 \mathrm{~min}$ to achieve uniform distribution of fibers through the mix.

Then, the coarse aggregate is added gradually during dry mixing. In the second step, one-third of the water content is added to the mixture. In the following step, the admixtures are added to the residual two-thirds of the water content then added to the mixture to achieve a slump greater than the final desired slump by $50 \mathrm{~mm}$. Finally, Chopped glass and steel fibers (representing low aspect ratio fiber $(L / d=25)$ are added in small increments by sprinkling them onto the surface of the mix until all the fibers were absorbed into the matrix. This technique was performed to prevent balling or interlocking of the fibers and achieve homogeneous dispersion of the fibers through the matrix. The freshly mixed concrete was tested for slump as a quality control test; the desired slump was $(100 \mathrm{~mm})$ to avoid segregation during casting and compaction. The mixed materials were then placed in the molds, compacted using external vibration, leveled, and cured in water for 28 days before testing according to the recommendations of ACI committee 544 (2011). Figure 1 represents the uniform distribution of fibers along the cross section of the tested specimens reflecting that, the fiber segregation was avoided and the desired homogeneity was achieved.

Cubes of $150 \times 150 \times 150 \mathrm{~mm}$ dimensions were prepared to be tested under static compression. Cylinders of $150 \mathrm{~mm}$ diameter and $300 \mathrm{~mm}$ height were prepared to be tested under indirect tension. The mean values and the standard deviations of compressive and tensile strengths of the hybrid FRCs are listed in Table 4.

For comparison, the mean values of compressive and tensile strengths for high strength concrete matrix with single fiber type addition tested by Sherbini (2014), with the same constituents properties and mix proportions as the current study, are listed in Table 5. It is clear that, the strengths of hybrid FRCs are higher than those of individual FRC. The compressive strength increased by (2-13\%), and the tensile strength increased (up to $14.8 \%$ ) in comparison with single fiber addition to concrete at the same fiber volume fraction. The keyword explaining that behavior is "synergy", i.e. synergistic effect.

Rao and Rao (2009) and Boulekbache et al. (2012), studied the effect of steel fiber geometry (fiber aspect ratio $=47$ (Rao and Rao 2009) and $65 \& 80$ (Boulekbache et al. 2012)) and matrix strength, i.e. $f_{c} \approx 20 \mathrm{MPa}$ (Rao and 


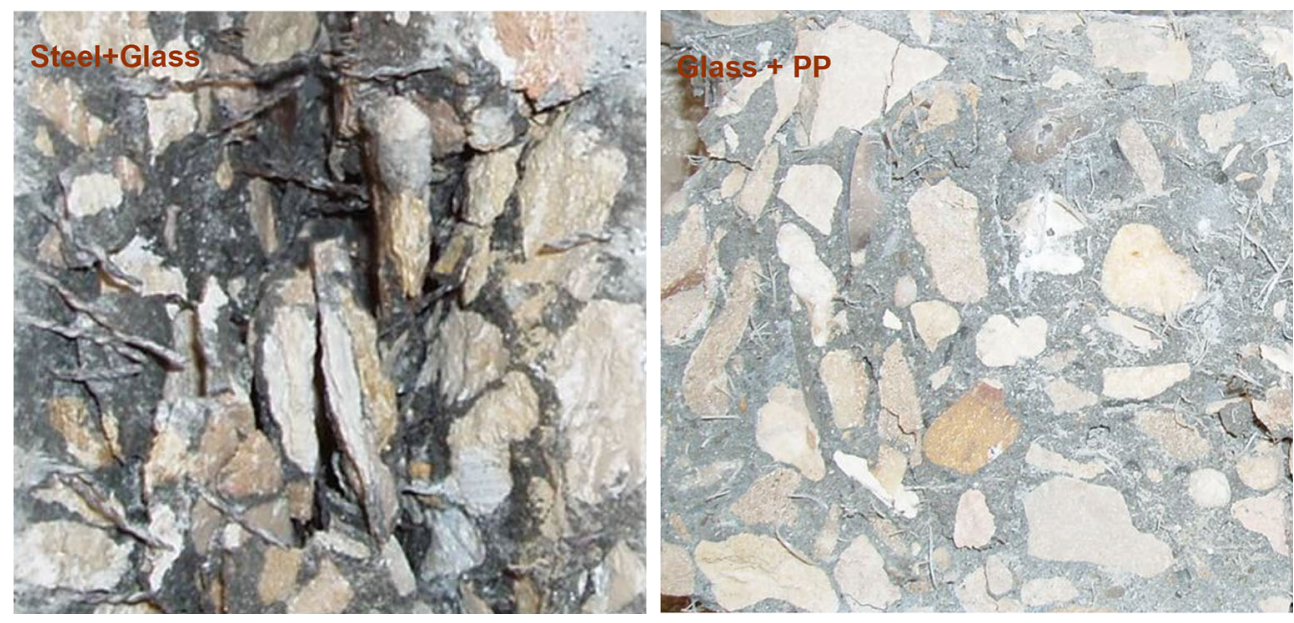

Fig. 1 Distribution of fibers along the cross section of the tested specimens.

Table 4 Mechanical properties of hybrid FRCs in MPa (Mean \pm SD).

\begin{tabular}{c|c|c|c|c}
\hline & $\mathrm{S} / \mathrm{G}$ & $\mathrm{S} / \mathrm{P}$ & $\mathrm{G} / \mathrm{P}$ & $\mathrm{S} / \mathrm{G} / \mathrm{P}$ \\
\hline \hline Compressive strength & $54.9 \pm 1.92$ & $56.2 \pm 2.04$ & $53 \pm 2.00$ & $54.5 \pm 1.67$ \\
\hline Tensile strength & $5.8 \pm 0.2$ & $6.2 \pm 0.18$ & $5.2 \pm 0.16$ & $5.1 \pm 0.16$ \\
\hline Shear strength (predicted) & 16.1 & 16.6 & 15.5 & 16 \\
\hline
\end{tabular}

Table 5 Compressive and tensile strengths in MPa (Sherbini 2014).

\begin{tabular}{c|c|c|c}
\hline & SRC & GRC & PRC \\
\hline \hline Compressive strength & 49.7 & 50.3 & 51.8 \\
\hline Tensile strength & 5.4 & 5.2 & 5.1 \\
\hline
\end{tabular}

Rao 2009) and $f_{c} \approx 29,60$, and $82 \mathrm{MPa}$ (Boulekbache et al. 2012), on shear behavior of fiber reinforced concrete. They concluded that (Rao and Rao 2009; Boulekbache et al. $2012)$, the ultimate shear strength of FRC $\left(\tau_{f}\right)$ is a function of $V_{f}^{\mathrm{o}} \%$ and the ultimate shear strength of concrete matrix $\left(\tau_{0}\right)$, $\tau_{0}=k \sqrt{ } f_{\text {co }}$ where $k$ is constant and $f_{\text {co }}$ is compressive strength of concrete matrix, i.e., $\tau_{f}=\tau_{0}+c\left(V_{f}^{\mathrm{o}} \%\right)^{\mathrm{n}}$ where $c$ and $\mathrm{n}$ are constants.

Rao and Rao (2009), measured compressive, tensile, and shear strengths of concrete, while, Boulekbache et al. (2012), measured only compressive and shear strengths of the reported three types of concrete. Furthermore, the mechanical property of concrete that is designed or controlled is typically its compressive strength, since this is the most important material characteristic in concrete specification and in building codes ( $\mathrm{Li}$ 2012). Therefore, in the present work regression analysis was carried out on their experimental data points of $\tau_{\mathrm{f}}$ and compressive strength of FRC $\left(f_{\mathrm{c}}\right)$ (Rao and Rao 2009; Boulekbache et al. 2012). Through regression analysis, the empirical relation obtained can be expressed.

$$
\tau_{f}=0.153 f_{c}^{1.163}
$$

Coefficient of determination $\left(R^{2}\right)$ of this proposed relation is 0.89 , suggesting a strong correlation between these two mechanical properties. In the present study, steel fiber represents the main fiber type due to its higher strength and stiffness, and for all hybrid FRCs except S/G/PP, the ration of $V_{f}$ of steel fiber to $V_{f}$ of other fibers is 2.0. Therefore, the current regression analysis of the results reported by Rao and Rao (2009) and Boulekbache et al. (2012) might herein be acceptable. According to the above equation, the predicted values of the present hybrid FRCs are tabulated in Table 4.

Concerning mode II of fracture (sliding mode), four test methods have been investigated; four point shear (4PS), Brazilian notched disc (BND), double notched cube (DNC), and double edge notched specimens (DENP), in a trial to avoid the limitations and sensitivity of each test. Test setups, layout, loading conditions, and specimens' dimensions are illustrated in Table 1. The main parameter affecting $K_{I I c}$ obtained from previous test setups are specimen geometry, size effect, constraint condition, and the notch depth to specimen width ratio $(a / w)$. Looking closer at these methods, it turned out that, most of them produce a mixed state of normal and shear stress mainly due to unavoidable load eccentricities, and hence bending moments which occur either from the beginning or after some deformation of the specimen.

To examine the reliability of these four mode II fracture toughness tests, the maximum undamaged defect size $\left(d_{\max }\right)$ suggested by Sallam (2003), Al Hazmi et al. (2012), Sallam et al. (2014), Sallam and Mubaraki (2015) will be compared 


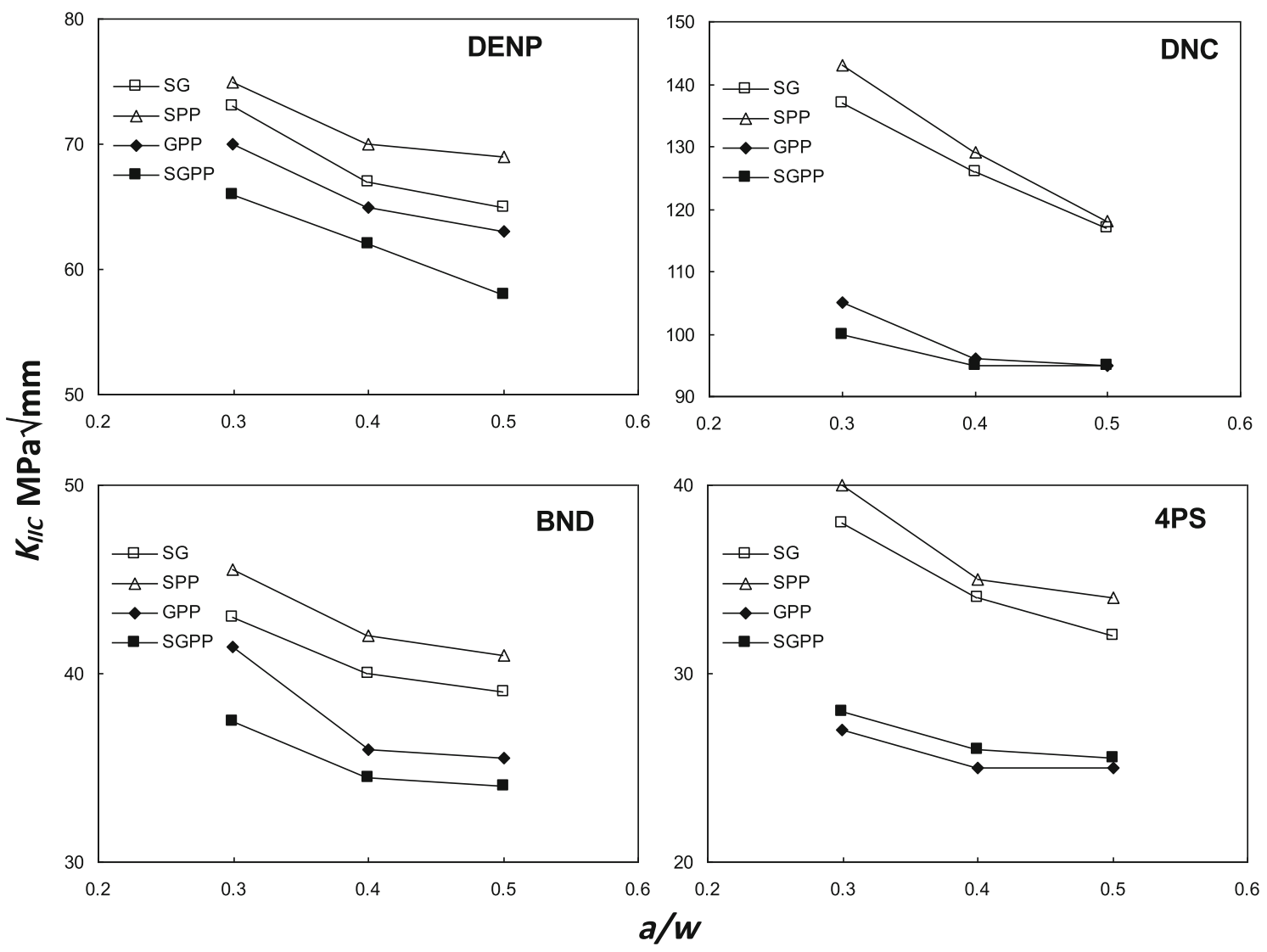

Fig. 2 Notch depth to specimen width ratio $(a / w)$ versus mode II fracture toughness $k_{I I c}$ for various test setups.
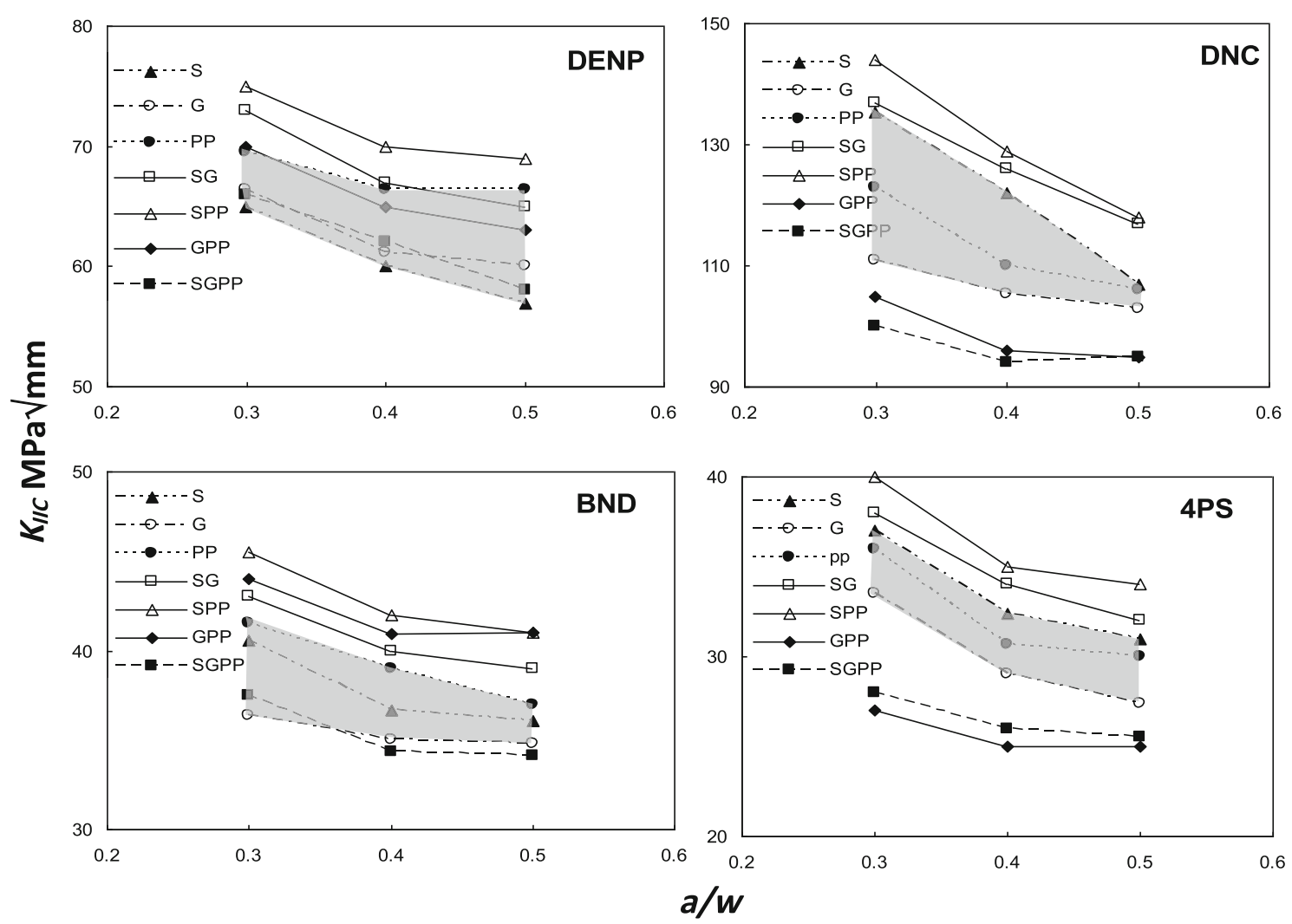

Fig. 3 Notch depth to specimen width ratio $(a / w)$ versus mode II fracture toughness $k_{I I c}$ for single and hybrid fiber reinforced concrete. 


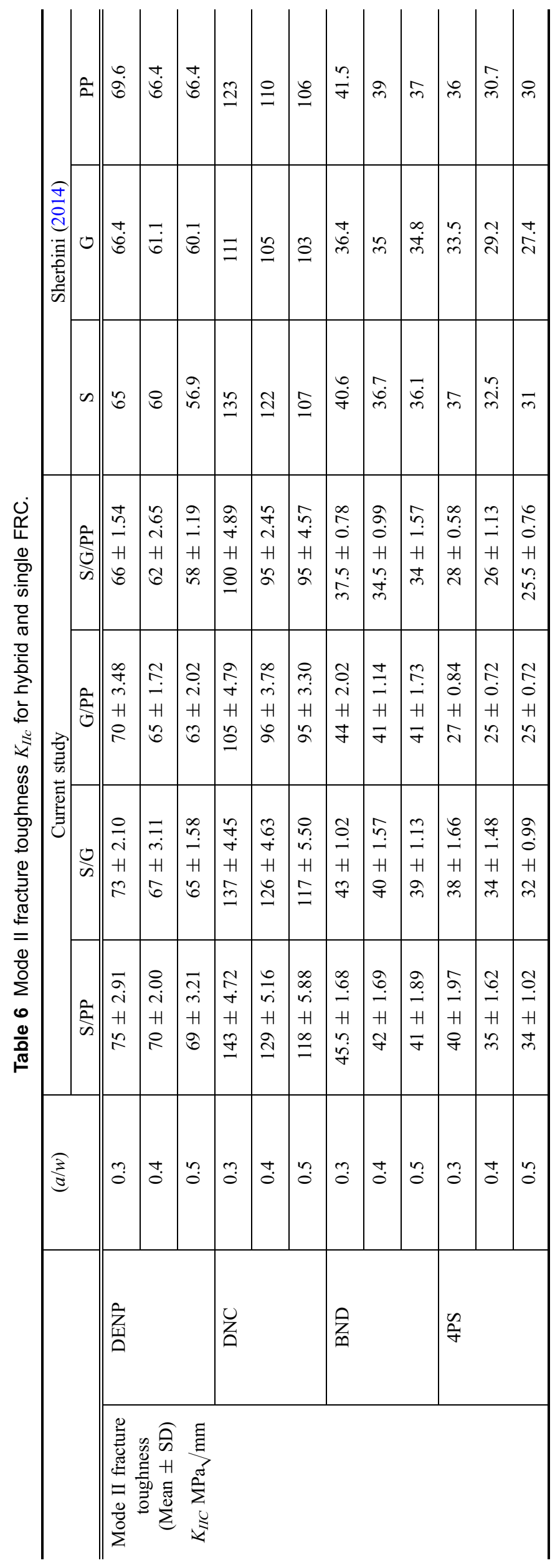

International Journal of Concrete Structures and Materials (Vol.9, No.4, December 2015) | 481 

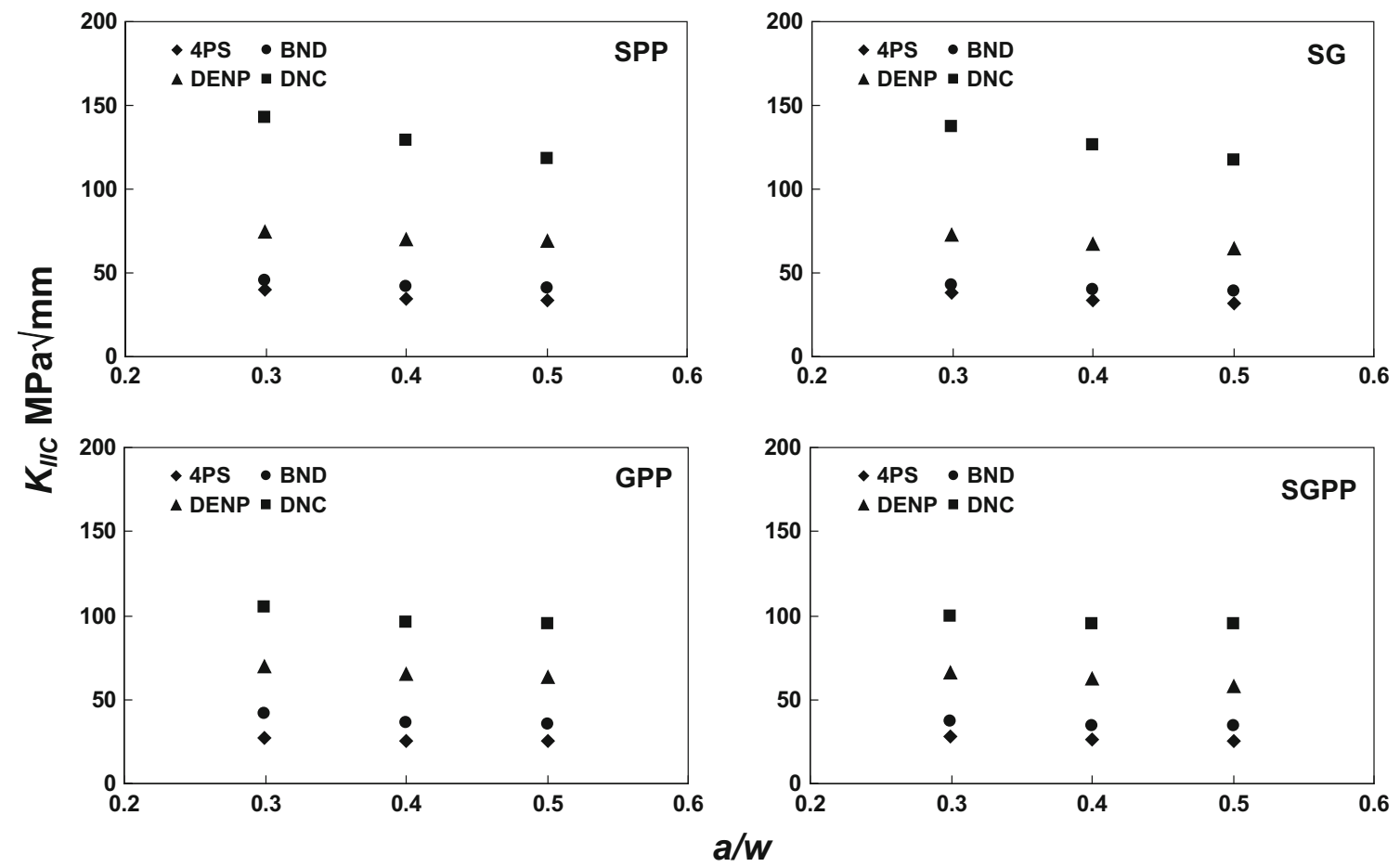

Fig. 4 Notch depth to specimen width ratio $(a / w)$ versus mode II fracture toughness $k_{I I c}$ for different hybridization patterns.

with the NMAS. Here, $d_{\max }$ is calculated by incorporating the strength of the material, $f$, instead of the critical applied stress along with the fracture toughness of the material, $K_{\mathrm{C}}$, hence, $d_{\max }$ instead of the notch depth is as follows:

$$
K_{C}=Y \sigma_{c r} \sqrt{\pi a}=Y f \sqrt{\pi d_{\max }}
$$

Applying this concept in the present case, i.e. $K_{C}=K_{I I C}$ and $f=\tau_{f}$, hence

$$
d_{\max }=\frac{1}{\pi}\left(\frac{K_{I I C}}{\tau_{f}}\right)
$$

\section{Results and Discussion}

A comparison between the values of $K_{I I c}$ of concrete according to four different test techniques is reported to make further assessment of the resulting data. Highlighting the effects of controlling the matrix fracture toughness, the fiber/matrix interface, and the matrix flaw size on the composite behavior might also enhance the production of engineered cementitious composites (ECC) (Li 2012).

Figure 2 shows the relation between $\mathrm{a} / \mathrm{w}$ and mode II fracture toughness $K_{I I c}$ for different test setups and hybridization patterns. For all hybrid patterns of FRC, a significant discrepancy of mode II fracture toughness $K_{\text {IIc }}$ values $(13-43 \%)$ is clearly observed with small values of $a /$ $w$, i.e. $a / w=0.3$. while it ranges from (19-24\%) with high values of $a / w$, i.e. $a / w=0.5$. This is evidence that mode II fracture toughness $K_{I I c}$ is affected by a non material characteristic parameter $(a / w)$, indicating that mode II fracture toughness $K_{I I c}$ in hybrid fiber reinforced concrete can not be assumed as a material property. Mode II fracture toughness $K_{I I c}$ is inversely proportional to $a / w$ for all concretes and test configurations, which strengthens the previous argument. This argument is in good agreement with the reported works by Swartz et al. (1988) and Reinhardt et al. (1997). By increasing $a / w$. The mode II fracture toughness $K_{\text {IIc }}$ decreasing rate reduces. This behavior may be due to that, by increasing $a / w$ both length and severity of crack increase, while the defense zone represented in the crack forehead ligament decreases.

Hybrid FRC containing steel fibers in combination of either glass or pp showed higher values of mode II fracture toughness $k_{I I c}$ than all other hybrid patterns, i.e. synergistic effect. The increment percentages ranges from (11.5-16\%) for DENP test (20-30\%) for DNC test (17-18\%) for BND test, and (25-30\%) for 4PS test. Steel fiber represents the fiber type with higher strength and stiffness, while either glass or pp fiber represents the relatively flexible type. In accordance with the 1st synergic mechanism (Hybrids based on fiber constitutive response), this hybridization pattern leads to improved toughness and strain capacity in the postcrack zone. For different test geometries the (S/PP) results are higher than those of all other hybridization patterns. The 2nd synergic mechanism (Hybrids based on fiber dimensions) explains that phenomenon, the pp fiber represents the smaller type that bridges micro-cracks and therefore controls their growth and delays coalescence leading to a higher tensile strength of the composite. Steel fiber represents the larger type that is intended to arrest the propagation of macro-cracks and therefore results in a substantial improvement in the fracture toughness of the composite. In this specific hybridization pattern $(\mathrm{S} / \mathrm{PP})$, a dual synergic 

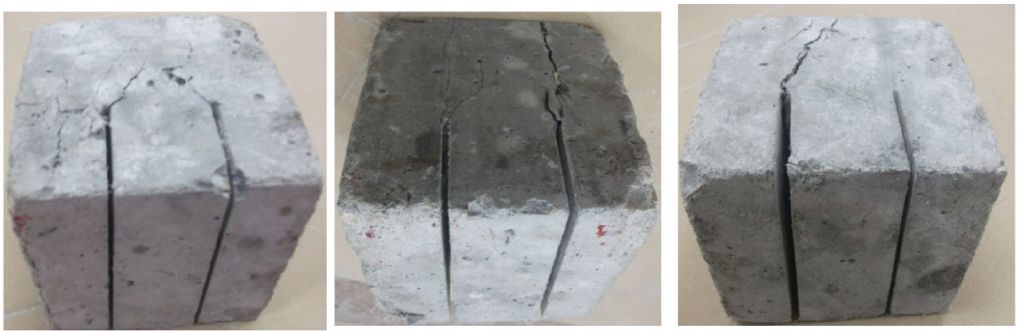

(a)

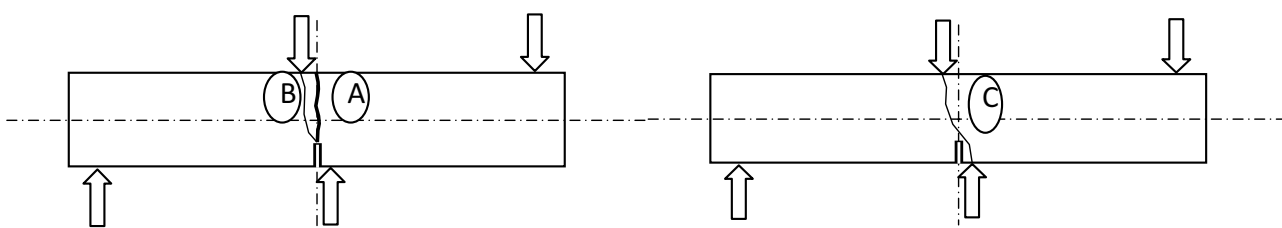

(b)
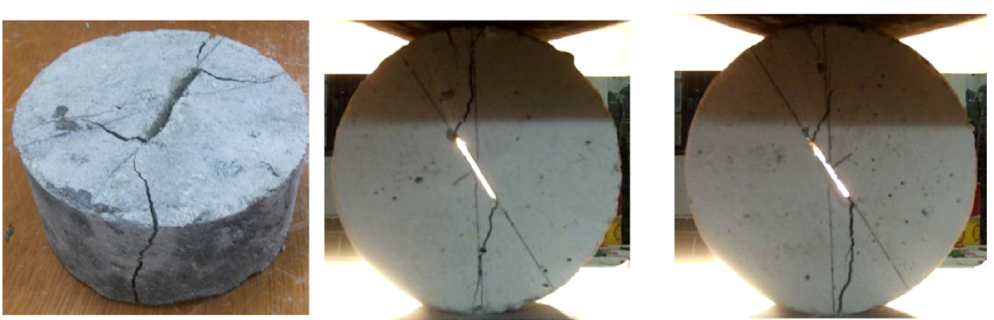

(c)
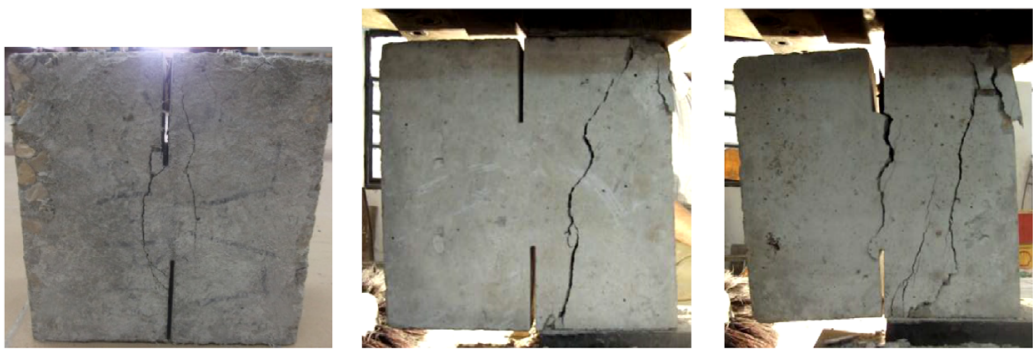

(d)

Fig. 5 Crack patterns in different mode II specimens under various test setups. a DNC specimens. b 4PS specimens. c BND specimens. d ENP specimens.

mechanism takes place resulting supreme values of mode II fracture toughness $k_{\text {IIc }}$. For different test setups, the (G/PP) showed lower mode II fracture toughness $k_{I I c}$. Both glass and $\mathrm{pp}$ are deficient in the required stiffness to provide reasonable crack propagation arrest. The S/G/PP hybrid FRC showed lower values of mode II fracture toughness $k_{\text {IIc }}$ for most geometries due to the reduction of $V_{f}$ of steel fiber from 1 to $0.5 \%$. For all hybrid FRCs except $\mathrm{S} / \mathrm{G} / \mathrm{PP}$, the ration of $V_{f}$ of steel fiber to $V_{f}$ of other fibers is 2.0, while, that ration is 1.0 in $\mathrm{S} / \mathrm{G} / \mathrm{PP}$ hybrid FRC. For both DNC and 4PS test setups, a wide gap between (S/PP \& S/G) on one hand and (G/PP \& S/G/PP) on the other hand is observed, which support the idea of dual synergic mechanism when adding steel fibers to the hybrid. In the other test setups DENP \& $\mathrm{BND}$, that gap exists but with narrower range.
In comparison with reported test results of single FRC by Sherbini (2014), the mode II fracture toughness $k_{\text {IIc }}$ values fitted in those gaps as shown in Fig. 3 for almost all geometries. The difference between compressive strengths for different hybridization patterns reported in the current study is minimal (less than $6 \%$ ), and does not reflect the wide discrepancy in the values of mode II fracture toughness $K_{\text {IIc }}$ (up to $43 \%$ ). In comparison with the previous study of single FRC reported by Sherbini (2014), the S/PP hybrid FRC pattern shows supreme behavior of both mechanical properties (compressive and tensile strengths) and mode II fracture toughness $K_{I I c}$.

Table 6 represents the mean values and standard deviations of mode II fracture toughness $K_{I I c}$ reported in the current study in comparison to the results of single FRC 
Table 7 Calculated values of $d_{\max } / \mathrm{NMAS}$.

\begin{tabular}{|c|c|c|c|c|c|c|}
\hline & & \multirow[t]{2}{*}{$(a / w)$} & \multicolumn{4}{|c|}{ Current study } \\
\hline & & & $\mathrm{S} / \mathrm{PP}$ & $\mathrm{S} / \mathrm{G}$ & $\mathrm{G} / \mathrm{PP}$ & $\mathrm{S} / \mathrm{G} / \mathrm{PP}$ \\
\hline \multirow[t]{12}{*}{$d_{\max } / \mathrm{NMAS}$} & \multirow[t]{3}{*}{ DENP } & 0.3 & 0.65 & 0.65 & 0.65 & 0.54 \\
\hline & & 0.4 & 0.57 & 0.55 & 0.56 & 0.48 \\
\hline & & 0.5 & 0.55 & 0.52 & 0.53 & 0.42 \\
\hline & \multirow[t]{3}{*}{$\mathrm{DNC}$} & 0.3 & 2.36 & 2.3 & 1.46 & 1.24 \\
\hline & & 0.4 & 1.92 & 1.95 & 1.22 & 1.12 \\
\hline & & 0.5 & 1.61 & 1.68 & 1.2 & 1.12 \\
\hline & \multirow[t]{3}{*}{$\mathrm{BND}$} & 0.3 & 0.24 & 0.23 & 0.26 & 0.17 \\
\hline & & 0.4 & 0.2 & 0.2 & 0.22 & 0.15 \\
\hline & & 0.5 & 0.19 & 0.19 & 0.22 & 0.14 \\
\hline & \multirow[t]{3}{*}{ 4PS } & 0.3 & 0.18 & 0.18 & 0.1 & 0.1 \\
\hline & & 0.4 & 0.14 & 0.14 & 0.08 & 0.08 \\
\hline & & 0.5 & 0.13 & 0.13 & 0.08 & 0.08 \\
\hline
\end{tabular}

previously found by Sherbini (2014) for the same concrete matrix. The sensitivity effect of the adopted test is almost the same in either single or hybrid FRC. Figure 4 shows that, the mode II fracture toughness $K_{I I c}$ measured from DNC test are the highest values due to the crack propagation miss alignment opposing sliding of crack surfaces. Figure 5a shows the different crack patterns of DNC specimens. However, the mode II fracture toughness $K_{\text {IIc }}$ values measured from 4PS test are the lowest as shown in Fig. 4. It is obvious that the common drawback of the 4PS mode II testing method is that, in the direction perpendicular to crack plane a tensile stress cannot be avoided, especially for crack pattern (c), as shown in Fig. 5b. Similarly in BND test as shown in Fig. 5c, the tensile stress component certainly causes a mode I stress intensity. For the materials with low tensile strength like concrete a small mode I stress intensity could result in tensile failure prior to shear failure in those specimen geometries employed in mode II tests. On the other hand, DENP specimens suffer from indirect tensile cracks near the main shear crack, as shown in Fig. 5d.

Maximum size of undamaged defect $\left(d_{\max }\right)$ is defined as, the maximum defect size that does not affect the material prosperities, i.e. the damage size beyond which, the material properties decreases. The values of $d_{\max }$ should be normalized to an internal structure parameter of concrete such as the NMAS. The values of $d_{\max }$ NMAS should not equal unity, i.e. $d_{\max }$ must be less than NMAS. On the other hand, $d_{\max }$ should not be of trivial value less than air voids in concrete. In the case of mode I fracture toughness, the value of $d_{\max }$ / NMAS was reported to be 0.7 by Sallam et al. (2014). On the present study, to check the reliability of the present results, $d_{\max }$ NMAS are calculated and tabulated in Table 7. It is clear that, the values of $d_{\max } / \mathrm{NMAS}$ in DNC test are greater than unity which is unacceptable. On the other hand, the values of $d_{\text {max }}$ /NMAS in 4PS test are very low, ranged from 0.08 to 0.18 . This may be attributed to the existence of tensile stress at the tip of mode II crack as mentioned above. $d_{\max }$ /NMAS ranged from 0.42 to 0.65 , and from 0.14 to 0.26 in DENP and BND test setups respectively, which represent acceptable values. Although DENP suffered from tensile cracks near the main shear crack, but still the most reliable test setup according to the non damage defect concept, i.e. The closer value to that obtained for Mode I (0.7) reported by Sallam et al. (2014).

\section{Conclusions}

The results of the present experimental work support the following conclusions:

1. Hybridization of fiber relatively increased compressive strength (2-13\%), and tensile strength (up to $14.8 \%$ ) in comparison with single fiber addition to concrete at the same fiber volume fraction.

2. Mode II fracture toughness of concrete $K_{\text {IIc }}$ decreased with the increment of $a / w$ ratio for all hybridization patterns and test setups (5-17.5\%).

3. Hybrid FRC containing steel fibers in combination of either glass or $\mathrm{pp}$ showed higher values of mode II fracture toughness $k_{I I c}$ than all other hybrid patterns. The increment percentages ranges from (11.5-16\%) for DENP test (20-30 \%) for DNC test (17-18\%) for BND test, and (25-30\%) for 4PS test.

4. Due to dual synergic mechanism, the (S/PP) mode II fracture toughness $K_{I I c}$ results are the highest among all other hybridization patterns.

5. Mode II fracture toughness $K_{\text {IIc }}$ of hybrid fiber reinforced concrete is found to be sensitive to $a / w$, geometry of test specimen, and loading condition. i.e., mode II fracture toughness $K_{I I c}$ of hybrid fiber reinforced concrete could not be assumed as a real material property. 
6. According to the non damage defect concept, DENP test setup is the most reliable test to measure pure mode II of concrete.

\section{Acknowledgments}

H. E. M. Sallam is on sabbatical leave from Materials Engineering Department, Zagazig University, Zagazig, 44519, Egypt.

\section{Open Access}

This article is distributed under the terms of the Creative Commons Attribution 4.0 International License (http://creativecommons.org/licenses/by/4.0/), which permits unrestricted use, distribution, and reproduction in any medium, provided you give appropriate credit to the original author(s) and the source, provide a link to the Creative Commons license, and indicate if changes were made.

\section{References}

ACI Commitee 544. (2011). Fiber reinforced concrete. Detroit, MI: American Concrete Institute.

Al Hazmi, H. S. J., Al Hazmi, W. H., Shubaili, M. A., \& Sallam, H. E. M. (2012). Fracture energy of hybrid polypropylenesteel fiber high strength concrete. HPSM, High Performance Structure and Materials, VI, 309-318.

Banthia, N., \& Gupta, R. (2004). Hybrid fiber reinforced concrete: Fiber synergy in high strength matrices. RILEM, Materials and Structures, 37(274), 707-716.

Banthia, N., Moncef, A., Chokri, K., \& Sheng, J. (1995). Uniaxial tensile response of microfiber reinforced cement composites. Journal of Materials and Structures, RILEM, 28(183), 507-517.

Banthia, N., \& Sheng, J. (1991). Micro reinforced cementitious materials, Materials Research Society Symposia Proceedings, Materials Research Society (Vol 211, pp. 25-32), Pittsburgh, PA.

Banthia, N., \& Soleimani, S. M. (2005). Flexural response of hybrid fiber reinforced cementitious composites. ACI Materials Journal, 102(6), 382-389.

Bentur, A., \& Mindess, S. (1990). Fiber reinforced cementitious composites. London, UK: Elsevier Applied Science.

Boulekbache, B., Hamrat, M., Chemrouk, M., \& Amziane, S. (2012). Influence of yield stress and compressive strength on direct shear behaviour of steel fibre-reinforced concrete. Construction and Building Materials, 27, 6-14.

Feldman, D., \& Zheng, Z. (1993). Synthetic fibers for fiber concrete composites, Materials Research Society Symposia Proceedings, Materials Research Society (Vol 305, pp. 123-128), Pittsburgh, PA.
Iosipescu, N. (1967). New accurate procedure for single shear testing of metals. Journal of Materials, 2(3), 537-566.

Irobe, M., \& Pen, S.-Y. (1992). Mixed-mode and mode II fracture of concrete. In Z. P. Bazant (Ed.), Fracture mechanics of concrete structures (pp. 719-726). New York, NY: Elsevier Applied Science.

Kamlos, K., Babal, B., \& Nurnbergerova, T. (1995). Hybrid fiber reinforced concrete under repeated loading. Nuclear Engineering and Design, 156(1-2), 195-200.

Kim, N. W., Saeki, N., \& Horiguchi, T. (1999). Crack and strength properties of hybrid fiber reinforced concrete at early ages. Transactions of the Japan Concrete Institute, 21, 241-246.

Larson, E. S., \& Krenchel, H. (1991). Durability of FRC-materials. Materials Research Society Symposia Proceedings, Materials Research Society, Pittsburgh, PA 211, 119-124.

Lawler, J. S., Zampini, D., \& Shah, S. P. (2002). Permeability of cracked hybrid fiber reinforced mortar under load. $A C I$ Materials Journal, 99(4), 379-385.

Lee, J., \& Lopez, M. M. (2014). An experimental study on fracture energy of plain concrete. International Journal of Concrete Structures and Materials, 8(2), 129-139.

Li, V. C. (2012). Tailoring ECC for special attributes: A review. International Journal of Concrete Structures and Materials, 6(3), 135-144.

Mobasher, B., \& Li, C. Y. (1996). Mechanical properties of hybrid cement-based composites. ACI Materials Journal, 93(3), 284-292.

Prokopski, G. (1991). Influence of water-cement ratio on microcracking of ordinary concrete. Journal of Materials Science, 26, 6352-6356.

Qian, C., \& Stroeven, P. (2000). Fracture properties of concrete reinforced with steel-polypropylene hybrid fibers. Cement \& Concrete Composites, 22(5), 343-351.

Rao, A. G., \& Rao, A. S. (2009). Toughness indices of steel fiber reinforced concrete under mode II loading. Materials and Structures, 42, 1173-1184.

Reinhardt, H. W., Josko, O., Shilang, X., \& Abebe, D. (1997). Shear of structural concrete members and pure mode II testing. Advanced Cement Based Materials, 5, 75-85.

Sallam, H. E. M. (2003). Fracture energy of fiber reinforced concrete. Al-Azhar University Engineering Journal, 6, $555-564$

Sallam, H. E. M., \& Mubaraki, M. (2015). Evaluation of the fracture energy methods used in fiber reinforced concrete pavements by the maximum undamaged defect size concept 94th Annual Meeting of TRB, Washington, DC.

Sallam, H. E. M., Mubaraki, M., \& Yusoff, N I Md. (2014). Application of the maximum undamaged defect size $\left(d_{\max }\right)$ concept in fiber-reinforced concrete pavements. Arabian Journal for Science and Engineering, 39(12), 8499-8506.

Shah, S. P. (1991). Do fibers increase the tensile strength of cementbased matrices. ACI Materials Journal, 88(6), 595-602.

Sherbini, A. S. (2014). Mode II fracture toughness estimates for fiber reinforced concretes using a variety of testing geometries. Engineering Research Journal, 37(2), 239-246. 
Swartz, S. E., Lu, L. W., Tang, L. D., \& Refai, T. M. E. (1988). Mode II fracture-parameter estimates for concrete from beam specimens. Experimental Mechanics, 28, 146-153.

Walton, P. L., \& Majumdar, A. J. (1975). Cement-based composites with mixtures of different types of fibers. Composites, 6, 209-216.
Watkins, J. (1983). Fracture toughness test for soil-cement samples in mode II. International Journal of Fracture, 23, RI35-RI38.

Xu, G., Magnani, S., \& Hannant, D. J. (1998). Durability of hybrid polypropylene-glass fiber cement corrugated sheets. Cement \& Concrete Composites, 20(1), 79-84. 